\title{
Metachronous Lung Cancer Developing after 11 Years of Chemo-Radiotherapy in a Patient with Non-Small Cell Lung Carcinoma
}

\author{
Onur Derdiyok*, Selma Aydogan, Murat Kavas, Cansel Atinkaya, Irfan Yalcinkaya \\ Department of Thoracic Surgery, Sureyyapasa Chest Diseases and Thoracic Surgery Training and Research Hospital, İstanbul, Turkey \\ Email: *onur_derdiyok@hotmail.com
}

How to cite this paper: Derdiyok, O., Aydogan, S., Kavas, M., Atinkaya, C. and Yalcinkaya, I. (2018) Metachronous Lung Cancer Developing after 11 Years of Chemo-Radiotherapy in a Patient with Non-Small Cell Lung Carcinoma. Open Journal of Thoracic Surgery, 8, 26-28. https://doi.org/10.4236/ojts.2018.82005

Received: March 31, 2018

Accepted: June 4, 2018

Published: June 7, 2018

Copyright $\odot 2018$ by authors and Scientific Research Publishing Inc. This work is licensed under the Creative Commons Attribution International License (CC BY 4.0).

http://creativecommons.org/licenses/by/4.0/

\begin{abstract}
The success rate of the chemo-radiotherapy is low for the patients with lung cancer. The risk of second primary malignancy (SPM) in lung cancer survivors is also not well reported in the literature. A 77-year-old male patient was given chemo-radiotherapy (KT_RT) 11 years ago because of the low respiratory function of the non-small cell lung cancer in the right lung. He applied to hospital for complaining cough. NSCLC was diagnosed and doctors performed left lower lobectomy to the patient. We presented the case in which the patient was cured after chemo-radiotherapy which is an extremely rare condition and the development of a second tumor 11 years later.
\end{abstract}

\section{Keywords}

Metachronous, Lung Cancer, Thoracic Surgery

\section{Introduction}

More than one or two primary lung cancers may develop synchronously or metachronically in the lung. Previous research showed that, regardless of developing time and location, the majority of the second primary lung malignancies are the same histological type. However, the recurrence of the second primary lung malignant tumor is very rare, especially with different histologic features. Metachronous tumors are different histologic type for the diagnosis or histologic type is the same if the disease-free survival rate is more than 2 years. The disease is detected in situ. The second cancer is in a different lobe or lung, or no metastasis. For the synchronous and metachronous tumors, the criteria defined by Martini, Melamed in 1975 and Antakliin 1995 are used [1]. We presented the case in which the patient was cured after chemo-radiotherapy and the develop- 
ment of a second tumor 11 years later.

\section{Case}

A 71-year-old man applied to our clinic for complaints of shortness of breath and numbness on the right hand 11 years ago. His history included tuberculosis treatment 20 years ago and 30 pack/year smoking history. He smoked 13 years ago. He had coronary artery disease. In 2004, the patient was diagnosed as squamous cell lung carcinoma by biopsy from the right upper lobe with fiberoptic bronchoscopy (FOB). However, the patient was treated with adjuvant chemotherapy paclitaxel, carboplatin cure and definitive radiotherapy due to limitation of pulmonary function tests. The patient then admitted to hospital complaining cough in 2015. His blood pressure was $130 / 85 \mathrm{~mm} / \mathrm{Hg}$, pulse was $90 / \mathrm{min}$, fever was $36.5^{\circ} \mathrm{C}$ and respiratory rate was $26 / \mathrm{min}$. Laboratory parameters were within normal limits. Thoracic computed tomography (CT) revealed a nodule in the left lower lobe that was uniformly sized and $19 \mathrm{~mm}$ in size (Figure 1). No endobronchial lesions were seen on the FOB examination. The nodule was found to have an SUV-max value of 18 at positron emission computed tomography (PET-CT). In pulmonary function tests were FVC: 3.58 lt, 103\%; FEV1: $2.73 \mathrm{lt}, 89 \%$. Left lower lobectomy was performed when squamous cell lung cancer was reported on frozen examination. The patient did not receive chemo-radiotherapy. He did well at 17-month follow-up.

\section{Discussion}

Pulmonary resection is currently the most effective treatment for patients with non-small cell lung cancer. However, patients undergoing curative surgical resection for primary lung cancer are also at risk of secondary primary lung cancer. Metachronous second primary lung cancer risk is $1 \%-2 \%$ /patient/year in patients after lung cancer resection [2].

A literature on curative therapy after chemo-radiotherapy has not been found. Our case is important both in this respect and in terms of observing metacronous tumor development coexistence after 11 years. It is estimated that $4 \%$ to $10 \%$ of all patients with non-small cell lung cancer (NSCLC) later have
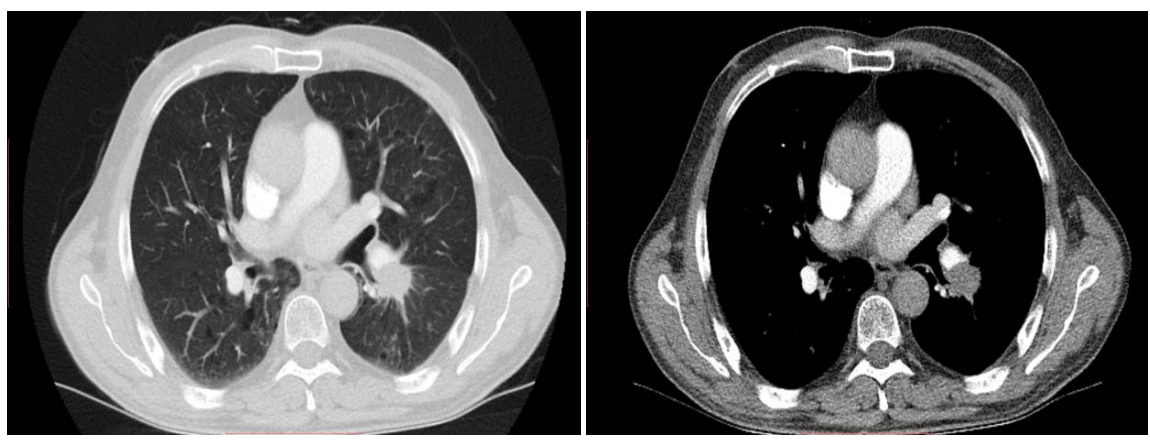

Figure 1. Thorax computed tomography (CT) shows a smoothly confined left lower lobe, nodule with a dimension of $22 \mathrm{~mm}$. 
metachronous [3]. The standard surgical treatment for patients with resectable small cell lung cancer is pulmonary lobectomy. There is no definitive guideline for surgical treatment for methachronous second primary lung cancer [1]. If the cardiopulmonary reserve is sufficient in metachronous tumors and if the previous operation is not pneumonectomy, lobectomy can be performed.

Metachronous tumors were found to have a 5-year survival rate of $33 \%$ and a 10 -year survival rate of $20 \%$, compared with primary lung cancers, but higher than metastases and synchronous tumors in resected metachronous tumors [4]. In recent years, introduction of various diagnostic methods and the development of new therapeutic agents and techniques may lead to recurrence or new cancers in one third of patients, especially in stage I non-small cell lung cancer. For this reason, the risk of second cancer increases as patients who initially appear to be early-stage lung cancer survive [5].

A common genetic history is common between the first lung cancer and the second primary lung cancer. Thus, the majority of secondary lung cancer is similar to the lung cancer initially presented in the histological type [6].

As a result, it should be reminded that metachronous or synchronous lung cancer may develop after the cured primer lung cancer treatment. The patients should follow for a long time for the risk of second primary lung tumours.

\section{References}

[1] Martini, N. and Melamed, M.R. (1975) Multiple Primary Lung Cancers. The Journal of Thoracic and Cardiovascular Surgery, 70, 606-612.

[2] Johnson, B.E. (1998) Second Lung Cancers in Patients after Treatment for an Initial Lung Cancer. Journal of the National Cancer Institut, 90, 1335-1345.

[3] Battafarano, R.J., Force, S.D., Meyers, B.F., Bell, J., Guthrie, T.J., Cooper, J.D. and Patterson, G.A. (2004) Benefits of Resectionfor Metachronous Lung Cancer. The Journal of Thoracic and Cardiovascular Surgery, 127, 836-842. https://doi.org/10.1016/j.jtcvs.2003.08.055

[4] Bhaskarla, A., Tang, P.C., Mashtare, T., Nwogu, C.E., Demmy, T.L., Adjei, A.A., Reid, M.E. and Yendamuri, S. (2010) Association for Academic Surgery Analysis of Second Primary Lung Cancers in the Seer Data Base. Journal of Surgical Research, 162, 1-6.

[5] Martini, N., Bains, M.S., Burt, M.E., et al. (1995) Incidence of Local Recurrence and Second Primary Lung Cancer in Resected Stage I Lung Cancer. The Journal of Thoracic and Cardiovascular Surgery, 109, 120-129. https://doi.org/10.1016/S0022-5223(95)70427-2

[6] Wang, X., Wang, M., MacLennan, G.T., et al. (2009) Evidence for Common Clonal Origin of Multifocal Lung Cancers. Journal of the National Cancer Institute, 101, 560-570. https://doi.org/10.1093/jnci/djp054 